Assistant Professor Medicine LUMHS, Hyderabad

Correspondence Address: Dr. Santosh Kumar

Assistant Professor Medicine LUMHS, Hyderabad

dr_santosh72@yahoo.com

Article received on: 10/09/2015 Accepted for publication: 08/01/2016

Received after proof reading: 09/02/2016

\section{HEADACHE; \\ PRIMARY VERSUS SECONDARY AND RELATIONSHIP WITH AGE, GENDER, HYPERTENSION, DIABETES AND OBESITY IN LUMHS HYDERABAD}

\begin{abstract}
Dr. Santosh Kumar
ABSTRACT... Objective and aims: To determines relationship of age, gender, hypertension, diabetes mellitus and obesity with primary and secondary headache in a tertiary care hospital. Study design: A cross-sectional study. Place and duration of study: Medical OPD of Liaquat University of Medical and Health Sciences, Hyderabad from 10January to 10 July 2015. Methodology: Patients (male and female) with complaint of headache in medical OPD were included in this study. Patients with acute emergency, stroke, meningitis, encephalitis and severe infection were excluded. After taking informed consent, history, examination and laboratory test (like fasting blood glucose, blood urea nitrogen) were sent. Data was recorded in a proforma. Data was entered and analyzed using SPSS version 20. Results: A total of 100 patients of headache were included in this study. The mean age of enrolled participants was $33.6 \pm 2$ years. Forty percent were male and $60 \%$ female with male to male ratio was $0.7: 1$. Eighty nine percent of patients have normal blood pressure, $82 \%$ normal blood sugar and $48 \%$ normal body mass index. Eighty six percent patients had primary and $14 \%$ had secondary headaches. Normal blood pressure was observed in $93 \%$ cases of primary headache compared to $64.3 \%$ in secondary headache ( $p-0.006)$. Normal blood sugar was observed in $14 \%$ cases of primary headache compared to $42.9 \%$ in secondary headache ( $p-0.018)$.normal body mass index was observed in $51.2 \%$ cases of primary headache compared to $28.6 \%$ in secondary headache ( $p$ 0.002). Conclusion: There is strong relationship of primary headache with age, gender, obesity but not associated with hypertension and diabetes mellitus. Hypertension and diabetes are more strongly related with secondary headache
\end{abstract}

Key words: Primary headache, out-patient department, age, gender.

Article Citation: Kumar S. Headache; primary versus secondary and relationship with age, gender, hypertension, diabetes and obesity in lumhs hyderabad. Professional Med J 2016;23(2):193-197. DOI: 10.17957/TPMJ/16.3051 to variability in care and may mean that people with headaches are not always offered the most appropriate treatments. People with alone are unlikely to have a serious underlying disease. ${ }^{4}$ Comparisons between people with headache referred to secondary care and those treated in primary care show that they do not differ in terms of headache impact or disability. Many people with headache do not have an accurate diagnosis of headache type. ${ }^{4}$ GP lack confidence in their ability to diagnose common headache disorders. They can feel under pressure to refer people for specialist opinion and investigation. Most common headache types can be diagnosed on clinical history and can be managed in primary care. ${ }^{5}$ Socrates defines nature of pain in scalp region, to severity, onset, 
character, associated factors, aggravating factors, and relieving factors. If specialist advice is needed on headache diagnosis and management this can be provided by a neurologist with an interest in headache or a GP with a special interest in headaches, or for young people under 18 years of age; a general hospital or community based pediatricians or pediatric neurologist. ${ }^{6}$ Within this guideline the term specialist is used to mean either a neurologist. Primary headache caused episodic, severe headache with aura or without aura presentation. Aura are usually visual changes lasting from minute to an hours, then follows with photophobia and phonophobia. ${ }^{7}$ Migraine that occurs more than 15 days per month at least 4 hours per day is consider chronic migraine. Why is it that those who have migraines just a few days per month often slowly progress to a chronic pattern? There are a number of possible reasons for this increase, some that can be changed and others that cannot. ${ }^{8}$ Using acute pain medicine is too frequently is a common reason for transformation to daily headache, but others include too much caffeine, snoring, and sleep apnea, thyroid disorders, head trauma, stress, depression, and anxiety, but for the purposes of this toolbox, we will be looking at obesity as a risk for chronic migraine normal weight people with migraine hereabout a $3 \%$ chance of developing chronic headaches in a year. If they are overweight, they have 3 times that chance.

\section{METHODOLOGY}

This cross sectional study was conducted in the Medical OPD of Liaquat University of Medical and Health Sciences, Hyderabad from 10 January to 10 July 2015.Patients (male and female) with complaint of headache in medical OPD were included in this study. Patients with acute emergency, stroke, meningitis, encephalitis and severe infection were excluded. After taking informed consent, history, examination and laboratory test (like fasting blood glucose, blood urea nitrogen) were sent. Data was recorded in a proforma.

Data was entered and analyzed using SPSS version 20.The mean and SD was calculated for age. Frequency and percentages were calculated for gender, hypertension, diabetes mellitus and obesity. Box plot was constructed for age. Comparison of type of headache was done by age, gender, hypertension, diabetes mellitus and obesity. Chi square test was applied by taking p-value of $<0.05$ statistically significant.

\section{RESULTS}

A total of 100 patients of headache were included in this study. The mean age of enrolled participants was $33.6 \pm 2$ years. Thirty percent patients were below 25 years of age. Forty percent were male and $60 \%$ female with male to male ratio was $0.7: 1$. Eighty nine percent of patients have normal blood pressure, $82 \%$ normal blood sugar and $48 \%$ normal body mass index. Eighty six percent patients had primary and $14 \%$ had secondary headaches.

Comparison between primary and secondary headache by age (figure 1), gender, hypertension, diabetes and obesity was summarized in table 1. Normal blood pressure was observed in $93 \%$ cases of primary headache compared to $64.3 \%$ in secondary headache ( $p-0.006)$. Normal blood sugar was observed in $14 \%$ cases of primary headache compared to $42.9 \%$ in secondary headache ( $p-0.018)$.normal body mass index was observed in $51.2 \%$ cases of primary headache compared to $28.6 \%$ in secondary headache ( $p$ 0.002).

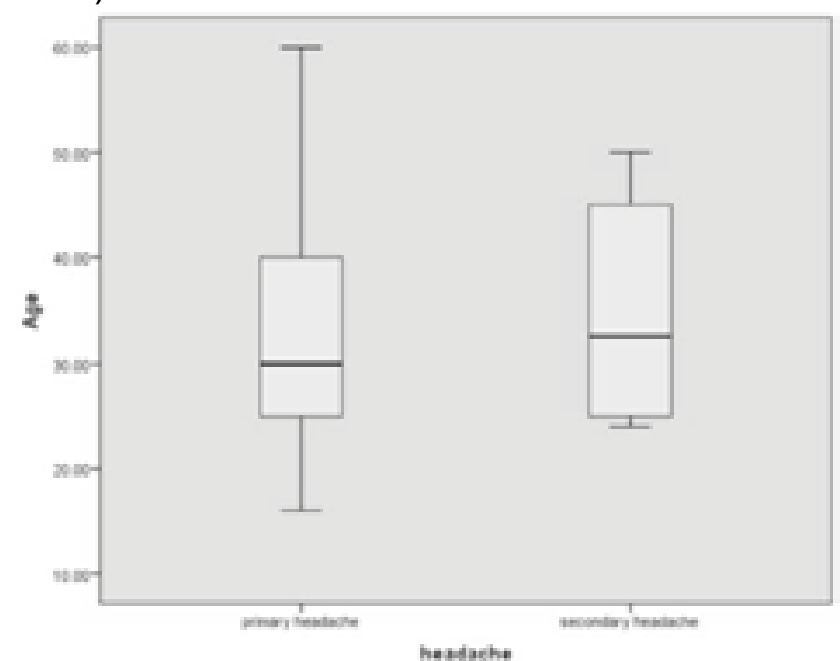

Figure-1. Age distribution among patients of primary and secondary headaches 


\begin{tabular}{|c|c|c|c|c|}
\hline & & \multicolumn{2}{|c|}{ Headache } & \multirow{2}{*}{ P-value } \\
\hline & & Primary headache & Secondary headache & \\
\hline \multirow{8}{*}{ Age } & \multirow{2}{*}{$<25$ years } & 26 & 4 & \multirow{8}{*}{0.642} \\
\hline & & $30.2 \%$ & $28.6 \%$ & \\
\hline & \multirow{2}{*}{$25-30$ years } & 22 & 3 & \\
\hline & & $25.6 \%$ & $21.4 \%$ & \\
\hline & \multirow{2}{*}{$31-40$ years } & 20 & 2 & \\
\hline & & $23.3 \%$ & $14.3 \%$ & \\
\hline & \multirow{2}{*}{$>40$ years } & 18 & 5 & \\
\hline & & $20.9 \%$ & $35.7 \%$ & \\
\hline \multirow{4}{*}{ Gender } & \multirow{2}{*}{ Male } & 33 & 7 & \multirow{4}{*}{0.295} \\
\hline & & $38.4 \%$ & $50.0 \%$ & \\
\hline & \multirow{2}{*}{ Female } & 53 & 7 & \\
\hline & & $61.6 \%$ & $50.0 \%$ & \\
\hline \multirow{6}{*}{ Hypertension } & \multirow{2}{*}{ Normal } & 80 & 9 & \multirow{6}{*}{0.006} \\
\hline & & $93.0 \%$ & $64.3 \%$ & \\
\hline & \multirow{2}{*}{ Grade $1 \mathrm{BP}$} & 4 & 3 & \\
\hline & & $4.7 \%$ & $21.4 \%$ & \\
\hline & \multirow{2}{*}{ Grade 2 BP } & 2 & 2 & \\
\hline & & $2.3 \%$ & $14.3 \%$ & \\
\hline \multirow{2}{*}{ Diabetes mellitus } & \multirow{2}{*}{ Yes } & 12 & 6 & \multirow{2}{*}{0.018} \\
\hline & & $14.0 \%$ & $42.9 \%$ & \\
\hline \multirow{8}{*}{ Obesity } & \multirow{2}{*}{ Normal } & 44 & 4 & \multirow{8}{*}{0.002} \\
\hline & & $51.2 \%$ & $28.6 \%$ & \\
\hline & \multirow{2}{*}{ Over weight } & 34 & 5 & \\
\hline & & $39.5 \%$ & $35.7 \%$ & \\
\hline & \multirow{2}{*}{ Obese } & 8 & 3 & \\
\hline & & $9.3 \%$ & $21.4 \%$ & \\
\hline & \multirow{2}{*}{ Morbid obesity } & 0 & 2 & \\
\hline & & $0.0 \%$ & $14.3 \%$ & \\
\hline
\end{tabular}

Table-I. Comparison of primary and secondary headache by age, gender, hypertension, diabetes and obesity

\section{DISCUSSION}

Headache at least once within a year, with the most recent prevalence estimates coming from GBD 2010 for migraine (14.7\%) and (20.1\%). ${ }^{12}$ No reliable global estimate is yet available for pmoh, because so few studies have been conducted and case-ascertainment is difficult, but a recent review found that estimates clustered around 1-1.5\% while all headache on $\geq 15$ days/month may affect $3 \%$ of adults. ${ }^{13}$ Comparisons with epidemiological studies elsewhere, using the same methods and questionnaire, put the prevalence estimate for migraine in Zambia towards the upper end of the range of these studies (India 25.2\% [unpublished],
Russia $20.8 \%$, china $9.3 \%$ ) and within the range for (India 35.1\% [unpublished], Russia 30.8\%, china $10.8 \%$ ). ${ }^{14-18}$ Therefore our zambian data are in contradiction of previous studies in ssa (surveying less representative populations) which reported substantially lower estimates for both migraine $(3.3 \%$ in rural benin ) and th $(7 \%$ in northern Tanzania. Primary headache is at least as common in zambia as in the rest of the world, which carries a very important public-health message for this country and probably the entire region. ${ }^{19-20}$

Migraine that occurs more than 15 days per 
month at least 4 hours per day is consider chronic migraine. Why is it that those who have migraines just a few days per month often slowly progress to a chronic pattern? There are a number of possible reasons for this increase, some that can be changed, and others that cannot. Using acute pain medi several studies have reported a different prevalence of headache types, which might be due to different methodologies used, as well as cultural and population characteristics of the studied patients. In a study of 418 patients with headache, found a prevalence of $39.9 \%$ for primary headaches. As expected, neuralgia had the highest prevalence. ${ }^{21}$

In middle age (40-49) and the peak prevalence of cluster headache was 30-39 years. According to our results, more than $75 \%$ of our patients had primary headaches, with migraine (with and without aura) being the most common type at $41.6 \%$ followed by the diagnosed in $34.1 \%$. consistent with our findings, in a retrospective study in Pakistan, showed migraine headache as the most common type, with a prevalence of $81 \%$ in our population My study determines $86 \%$ of patients have primary headache (migraine) with normal blood pressure (normal BP 88\%) and $13 \%$ have secondary headache mostly caused by hypertension (BP 10\%), 1\%pts is missing from study (table I) and bar chart 1 . Out of 100 patients BMI (body mass index) were found $48 \%$ have normal, $39 \%$ have over weight and $11 \%$ have obesity and $2 \%$ have morbid obesity. ${ }^{22}$ Cine is too frequently is a common reason for transformation to daily headache, but others include too much caffeine, snoring, and sleep apnea, thyroid disorders, head trauma, stress, depression, and anxiety, but for the purposes of this toolbox, we will be looking at obesity as a risk for chronic migraine normal weight people with migraine hereabout a $3 \%$ chance of developing chronic headaches in a year. If they are overweight, they have 3 times that chance. ${ }^{23}$

\section{CONCLUSION}

There is strong relationship of primary headache with age, gender, obesity but not associated with hypertension and diabetes mellitus. Hypertension and diabetes are more strongly related with secondary headache.

Copyright (C) 08 Jan, 2016.

\section{REFERENCE}

1. Headaches: diagnosis and management of headaches in young people and adults [internet].e of physicians (uk); 2012 Sep.

2. Katsarava Z, Kukava M, Mirvelashvili E, Tavadze A, Dzagnidze A, Djibuti M, Steiner TJ. A pilot methodological validation study for a populationbased survey of the prevalence of migraine, tensiontype headache and chronic daily headache in the country of Georgia. J Headache Pain. 2007;8:77-82.

3. Rao GN, Kulkarni GB, Guru RG, Rajesh K, Subbakrishna $D K$, Steiner TJ, et al. The burden of headache disorders in india: methodology and questionnaire validation for a community-based survey in karnataka state. $J$ Headache Pain. 2012;13:543-50.

4. Yu SY, Cao XT, Zhao G, Yang XS, Qiao XY, Fang YN, et al. The burden of headache in china: validation of diagnostic questionnaire for a population-based survey. J Headache Pain. 2011;12:141-6.

5. Lampl C, Steiner TJ, Mueller T, Mirvelashvili E, Djibuti M, Kukava M, et al. Will (or can) people pay for headache care in a poor country? J Headache Pain. 2011;13:6774.

6. Hu XH, Markson LE, Lipton RB, Stewart WF, Berger ML. Burden of migraine in the united states. Disability and economic costs. Arch Intern Med.1999;159:813-8.

7. Bigal ME, Rapoport AM. Obesity and chronic daily headache. CurrPain Headache Rep. 2011;16:101-9.

8. Yu S, Liu R, Zhao G, Yang X, Qiao X, Feng J, et al. The prevalence and burden of primary headaches in china: a population-based door-to-door survey. Headache. 2012;52:582-91.

9. Ayzenberg I, Katsarava Z, Sborowski A, Chernysh M, Osipova V, Tabeeva G, etal. The prevalence of primary headache disorders in russia: a countrywide survey. Cephalalgia. 2012;32:373-81.

10. Demarin V, Vukovic V, Lovrencic- Huzjan A. Evidence based guidelines for the treatment of primary headaches. Act Med Croatia. 2008;62:99-136.

11. Ravishankar K, Chakrarty A, Chowdhury D, Shukla R, Singh S. Guidelines on the diagnosis and the current management of headache and related disorders. Ann Indian AcadNeurol. 2011;14(suppl. 1):s40-s59. 
12. Canadian headache society prophylactic guidelines development group. Canadian headache society guideline for migraine prophylaxis. Can Jneurol Sci. 2012;39(2 suppl. 2):1-62.

13. Holroyd KA, Cottrell CK, O'donnell FJ, Carlson BW, et al. Effect of preventive (beta blocker) treatment, behavioral migraine management, or their combination on outcomes of optimized acute treatment in frequent migraine: randomized controlled trial. BMJ. 2010;341:c4871.

14. Kruszewski P, Bieniaszewski L, Neubauer J, KrupaWojciechowska B. Headache in patients with mild to moderate hypertension is generally not associated with simultaneous blood pressure elevation. J Hypertens. 2000;18:437-44.

15. WieheM. Migraine is more frequent in individuals with optimal and normal blood pressure pressure: a population-based study. J Hypertens. 2002;20:13036.

16. Massie BM. Systemic Hypertension. In: Tierney L, Mcphee S, Papadakis M (eds). Current medical diagnosis and treatment. Mcgraw-hill companies: new york, 2002, pp 459-484.

17. Pickering T. Headache and hypertension. Something old, something new. J ClinHypertens. 2000;2:345-7.

18. Steiner Tj, Gururaj G, Andrée C, Katsarava Z, Ayzenberg $\mathrm{I}, \mathrm{Yu}$ S-Y, et al. Diagnosis, prevalence estimation and burden measurement in population surveys of headache: presenting the hardship questionnaire. $J$ headache pain. 2014;15:3.

19. Ayzenberg I, Katsarava Z, Mathalikov R, Chernysh M, Osipova V, Tabeeva G, et al. The burden of headache in Russia: validation of the diagnostic questionnaire in a population-based sample. Eur j neurol. 2011;18:4549.

20. Yu SY, Cao XT, Zhao G, Yang Xs, QiaoXy, Fang Y-N, et al. The burden of headache in china: validation of diagnostic questionnaire for a population-based survey. J headache pain. 2011;12:141-6.

21. Rao GN, Kulkarni GB, Gururaj G, Rajesh K, Subbakrishna DK, Steiner TJ, et al. (2012) the burden of headache disorders in India: methodology and questionnaire validation for a community-based survey in karnataka state. J headache pain. 2012;13:543-50.

22. Gururaj G, Kulkarni GB, Rao GN, Subbakrishna DK, Stovner LJ, Steiner TJ. Prevalence and sociodemographic correlates of primary headache disorders: results of a population-based survey from Bangalore, India. Indian j publ health. 2014;58:241-8.

23. Herekar AD, Herekar AA, Ahmad A, Uqaili UL, Ahmed $B$, Effendi J, et al. The burden of headache disorders in |Pakistan: methodology of a population-based nationwide study, and questionnaire validation. J headache pain. 2013;14:73.

\section{PREVIOUS RELATED STUDY}

Qamar S Khan, Shaikh Mohammad Shan-e-Din. CHRONIC HEADACHE; THE ROLE OF WATER VIEW IN RADIOLOGY (Original) Prof Med Jour 15(4) 508-511 Oct, Nov, Dec, 2008.

Tariq Mahmood Malik, Amjad lqbal, Muhammad Asghar Khan. POST SPINAL HEADACHE; COMPARING NEEDLES OF 25 AND 27 GAUGES FOR INCIDENCE OF POST SPINAL HEADACHE (Original) Prof Med Jour 14(3) 441-447 Jul, Aug, Sep, 2007.

\section{AUTHORSHIP AND CONTRIBUTION DECLARATION}

\begin{tabular}{c|l|l|l|}
\hline Sr. \# & \multicolumn{1}{|c|}{ Author-s Full Name } & Contribution to the paper & Author=s Signature \\
\hline 1 & Dr. Santosh Kumar & Author Researcher & \\
\hline
\end{tabular}

